\title{
Ecosystems services research in action: reflexively valuing environments in the South Pacific
}

\author{
Chelsea E. Hunter ${ }^{1}$ and Matthew Lauer ${ }^{2}$
}

\begin{abstract}
Ecosystem services (ES) are heralded as an approach that communicates across disciplines and between researchers and resource managers, encouraging more environmentally sustainable human behavior. However, most studies presuppose that "values" are ontologically distinct from "ecosystem services" without examining what this framing enables and occludes about human and otherthan-human relations. Through a reflexive research approach, we conduct a conventional photo elicitation ES survey among four groups in Moorea, French Polynesia, while also eliciting respondents' evaluations of the survey method, and documenting the method in action as participants interacted with it. Photo elicitation results suggest that fishers valued the subsistence fishery while scientists favored habitats, yet all stakeholders were concerned about the role of economic activities in contributing to environmental degradation. Yet, survey participants had difficulties with interpreting the photos of ecosystem services as intended, an indication that the ES framework commits to a nature-culture dualism and displaces other ways of ordering human and other-than-human relations, particularly those present throughout the Global South. We argue that ecosystem services research is best treated as a situated practice where researcher and research participants jointly produce intended and unintended results and outcomes.
\end{abstract}

Key Words: cultural ecosystem services; nature-cultural dualism; Pacific; reflexive methods

\section{INTRODUCTION}

Assessing and understanding the value of ecosystems has become a major field of interest in environmental management (Costanza et al. 1997, Daily 1997, Norgaard 2010). Largely, this is because of its assumed role as a boundary object that enables communication across scientific disciplines as well as research and policy arenas (Steger et al. 2018). The framework that many policy makers, researchers, and conservation practitioners employ to guide their interrogations into ecosystem values is that of ecosystem goods and services (ES), especially as it has been outlined in the Millennium Ecosystem Assessment framework (MEA 2003). The ES framework gathers diverse scientific and policy audiences around a common theme despite groups adhering to different schools of thought over its purpose. Environmental economists, for example, assume that environmentally damaging behavior is due to externalized costs and by valuing these externalities and including them in the economic calculus, destructive behavior will become more expensive. Conservation practitioners, on the other hand, see ES as a way to demonstrate the value(s) of ecosystems and to motivate conservation.

The key strengths of ES is that it places explicit attention on how human societies are fundamentally dependent on nature for their well-being, where nature is envisioned as a fixed stock of natural capital that provides a limited flow of services to humans. The ES framework has fostered transdisciplinary research, by producing composite value indicators of ecosystem services that are comparable across different contexts. Typically, ecosystem services are divided into four overarching categories to capture a wide range of environmental dynamics. These domains include (1) provisioning services such as food and water; (2) regulating services that control climate and water resources; (3) underlying supporting services such as photosynthesis and nutrient cycling; and (4) cultural services such as aesthetic, spiritual, or recreational values (MEA 2003). Through uncovering specific benefits that ecosystem services provide people, ES frameworks seek to convince policy makers and sway the wider public that ecosystems are worth protecting (Costanza et al. 1997, Daily 1997, Norgaard 2010).

A growing literature, however, has revealed limitations of the ES concept (Raymond et al. 2013, Barnaud and Antona 2014, Schröter et al. 2014, Kull et al. 2015). A key critique is that ES relies on the notion that people's values, on the one hand, and ecosystem services, on the other, are ontologically distinct, universal domains rather than one way among many of dividing up the world (Turnhout et al. 2013, sensu Descola 2013). Anchored in several centuries of scientific thought, ES research has assumed that the biophysical realm exists as an inert and universal layer of reality upon which humans project their creative and highly variable systems of meaning. This unprecedented and highly productive ontological commitment, known as the natureculture dichotomy, is foundational to most western science and modernity more generally (Latour 1991).

In response to these and other critiques, ES scholars suggest that more explicit attention needs to be directed toward cultural ecosystem services, described most commonly as cultural heritage, landscape aesthetics, or spiritual significance (Daniel et al. 2012, Gould et al. 2015, Hirons et al. 2016). More recently, research into cultural ecosystem services has inspired "relational values," an analytic that proposes a third values category to promote environmental protection and to overcome a long standing debate about the extent to which nature should either be protected for its own sake or for the benefits it provides to humans (Chan et al. 2012, Himes and Muraca 2018). This has led to a growing literature on relational values and its addition to the IPBES framework on ecosystem services (Chan et al. 2018).

We welcome these calls to develop more sensitive and detailed conceptualizations of value regimes because they signal a recognition that specific framings of social-natural relations 
imposed by much ES research displaces or renders invisible those structures of thought and action ordered around different principles. Nevertheless, these innovations continue to assign other-than-human nature a different ontological status than human values. This is expressed without ambiguity when the authors of an influential ES article state: "The structures and functions produced and sustained by ecosystems arguably exist independent of human needs, and they are, in principle, equally concrete and quantifiable..." (Daniel et al. 2012:8813). Certainly the relational values concept is more encompassing with its emphasis on exploring the value of the relations between humans and nature rather than just the objects, i.e., humans and nature, themselves. However, the relational values model, like ES research more generally, authorizes and reinforces those objects, humans and nature, as the universal dyad that produces the identifiable relations. The addition of a third relational dimension to the nature-culture dichotomy most certainly produces new space for describing additional modalities and ways of being, although those that do not adhere to the dualist schema will most likely remain illegible. In other words, the relational values approach does not establish a new ontological commitment, but instead reinforces the nature-culture dichotomy albeit with additional, and important, avenues of inquiry.

One such region where people have been known not to assume the world can be reduced to two heterogeneous orders of reality is the Pacific. Much ethnographic literature suggests, for example, that for Islanders, land and sea ecological zones, human identities, and ancestors, constitute an assemblage where the order of beings blurs biophysical and cultural or social domains (Ward and Kingdon 1995, Lauer and Aswani 2009, Bambridge 2012). Indeed, Pacific Island languages have terms like voana (Fiji), ahupua'a (Hawaii), gusu (Solomon Islands), and fenua (Society Islands) that demarcate a biophysical area of land and sea resources as well as local history, habitation, people's identities, and multitudes of other-than-human entities that we call ghosts or spirits (Hviding 2003, Lauer 2014). These social and biophysical units are usually triangle-shaped and extend from ridgetop out across shallow coastal or lagoon areas and barrier reefs into open ocean. These units do not simply delimit the resources and ecosystems contained in an area; instead they contain those ecosystems and a myriad of other human and otherthan-human manifestations, entities, and processes. Voana, for example, translates to "tribe" or kin-based group and the specific name of a voana usually is the autonym of the inhabiting social group. Thus, Pacific Islanders, and many other non-Western peoples, establish relations between themselves and other beings in a social-ecological assemblage that does not necessarily carve out social and natural domains that neatly fit the separation of nature and culture implied by the ES framework. Rather than presupposing that these descriptions are admirable examples of cultural diversity, what if instead they were a form of composition whereby a world is assembled?

In this research our approach is explicitly experimental. Instead of assuming that our account could provide a clear, purified description of how people, in our case four groups on Moorea, French Polynesia, superimpose their values on ecosystem services, we instead conducted a conventional ES study and observed it in action. If, as we argue above, ES carries with it a certain ordering of the world, our goal in this research is to describe what the approach produces as Polynesians and other stakeholders on Moorea interact with it. Put differently, we envision ES research, like all research, not as a neutral procedure that stands above the researched, but as a situated practice (Lauer and Aswani 2009) or method assemblage (Law 2004) that produces situated knowledge (Haraway 1988), a knowledge that is locatable, partial, and critical, and that can be held accountable for its findings. The four groups on Moorea, designated by their profession, were professional fishers, scientists, tourism operators, and other, which we refer to as the general population. Although we were explicitly interested in comparing values between professional fishers, scientists, and tourism operators, we also wanted to compare how Moorean residents from any professional background valued the environment, thus leading to the general population category. We selected these groups because they all have vested interests in and frequent interactions with the marine environment, but which, because of their professions, differ in meaningful ways. We first conducted a conventional ES methodology where we had participants assign values to photographs representing 11 different ecosystem services. Second, we carefully documented how participants engaged with the survey in practice. Finally, we asked survey participants openended questions about the quality and feasibility of the survey methodology itself. We argue that ES research should be treated as a situated practice, where values are not pre-ordained but collaboratively identified, in turn, reflecting a view from somewhere (sensu Haraway 1988).

\section{STUDY SITE AND POPULATION}

Moorea is a $134 \mathrm{~km}^{2}$ high-volcanic island located $25 \mathrm{~km}$ west of Tahiti in the Society Islands archipelago (Fig. 1). The island is encompassed by a $29 \mathrm{~km}^{2}$ coral reef-lagoon system that is broken up by 11 passages in the barrier reef. Because of the steep, verdant, and rugged peaks of the island interior, the majority of the population is concentrated around the coastal strip (Salvat and Pailhe 2002). The long-term relationships that Polynesians have held with island environments has led to them having an outwardlooking perspective, understanding the land and sea as an interconnected whole (Hviding 2003).

The coral reefs of Moorea support some of the highest levels of fish consumption documented in the Pacific (Yonger 2002). Moorean residents consume on average $110 \mathrm{~kg}$ of fish a year (Yonger 2002), compared to an average of $23 \mathrm{~kg}$ in other regions of the Pacific (Labrosse et al. 2006). However, the importance of these rates of fish consumption are not reflected in recent valuations of Moorea's reefs. A 2015 valuation demonstrated that Moorea's reefs held a recreational value of 27 million Euros. Conversely, fishing was valued at 4 million Euros, 2.8 million Euros of which were fish that were consumed in households (Pascal and LePorte 2015). The importance of consuming coral reef fish to Tahitian identity is also not reflected in these figures. Eating foods classed as Tahitian, such as certain reef fish species, is central to Tahitian identity (Levy 1973). We use the term Tahitian throughout this paper to refer to the autochthonous Polynesian residents of Moorea. For Mooreans, consuming these fish may be as important to Tahitian identity as speaking the Tahitian language (Leenhardt et al. 2016). Thus the fishery of Moorea exemplifies how difficult it can be to quantify the cultural values of the reef when the act of fish consumption itself is a way to reinforce Polynesian identity in the face of neo-colonial 
Fig. 1. The location of the Society Islands and Moorea. The coral-reef lagoon ecosystem that surrounds the island is highlighted in gray and black.

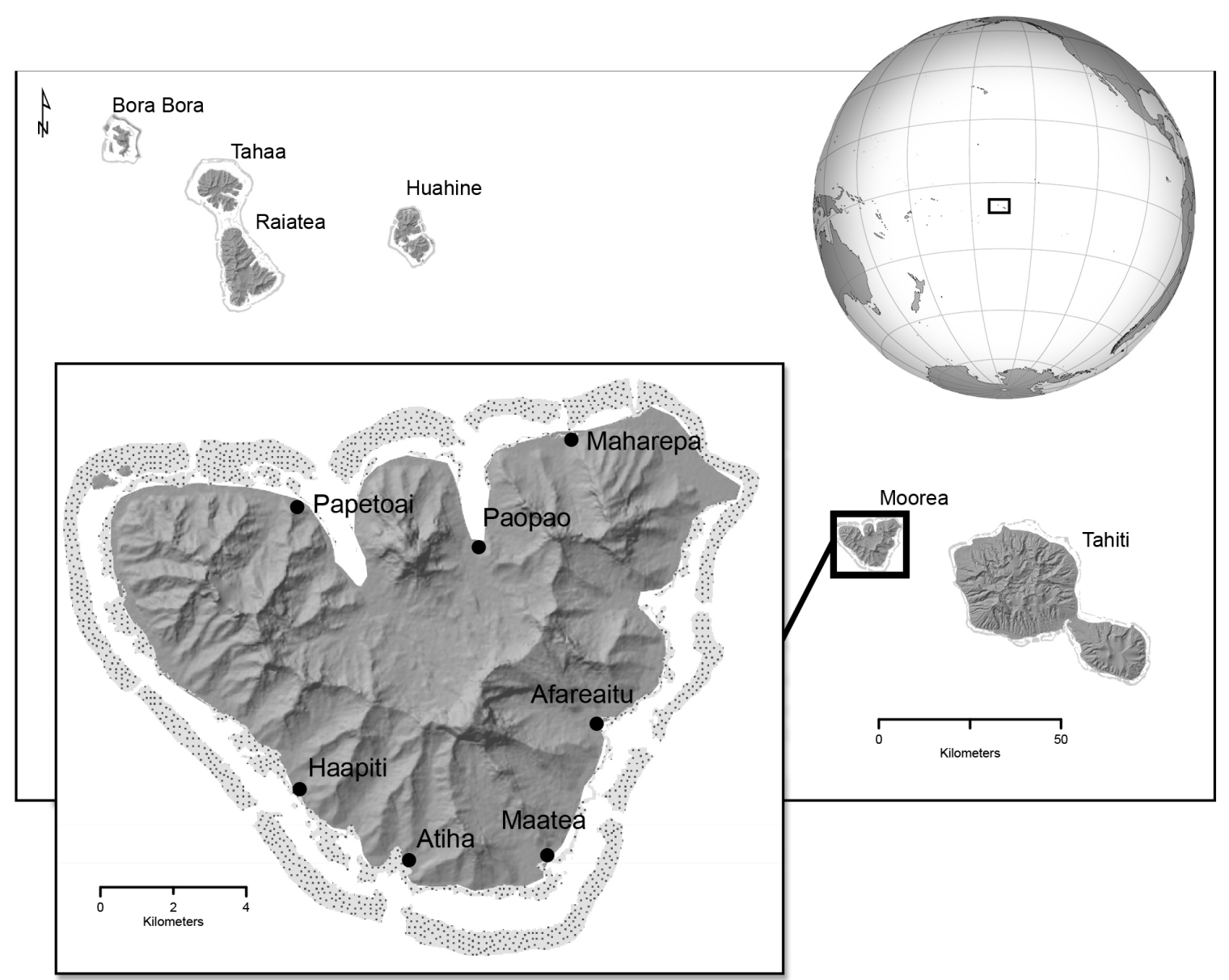

pressures. In part, these pressures stem from the shift from subsistence economies to market economies, such as tourism, under French colonialism (Hemmingham 1992).

Tahitians have used tourism as a way to strengthen their own cultural heritage and identity alongside a monetary economy (Castri 2002). French Polynesia is heavily dependent on tourism, building off of the "myth of Tahiti" that has transformed the Western imaginary of the region as the islands of love (Kahn 2011). The turquoise lagoons that surround the island serve to draw in tourists, captivated by the warm waters and white sand beaches that are promoted through the marketing materials of the tourism bureau of the country (Salvat and Pailhe 2002, Kahn 2011). Tourism operators in French Polynesia focus their marketing efforts on marine-centric activities to draw in tourists. The proximity of Moorea to Papeete, Tahiti, the capital of French Polynesia and the site of the country's major international airport, has led to Moorea becoming like a suburb of Papeete and a destination for the majority of tourists who visit the region (Walker and Robinson 2009).

Moorea is also the focus of some the world's most extensive coral reef research and hosts two world class research centers (Trapon et al. 2011). The French government established the Centre de
Recherches Insulaires et Observatoire de l'Environnement (CRIOBE) in 1971. Americans began the U.C. Berkeley Richard B. Gump station (Gump) in 1985. Gump is the home of the Moorea Coral Reef Long-Term Ecological Research (LTER) site, a U.S. funded program that has systematically monitored Moorea's reefs since 2004. Both stations host students and faculty from different international universities, though primarily from the United States and Europe. Taken together, scientists, tourism operators, fishers, and the general population of Moorea interact intensively with the island's coral reef-lagoon ecosystem. Each group having vested interests and transformative experiences in the marine environment.

\section{RESEARCH DESIGN}

We conducted surveys among four profession groups, including: the general population $(n=56)$; professional fishers $(n=14)$ who are also referred to as fishers from here forward; scientists ( $\mathrm{n}=$ 20) from both CRIOBE and Gump; and tourism operators ( $n=$ 10). The participants from the fisher and general population categories were located in the Southern Haapiti and Papetoai districts. Tourism operators were interviewed in the districts of Afareaitu, Pao Pao, Haapiti, and Papetoai. 
Our research involved three components. First, we adhered to conventional ES methods and designed a survey to isolate specific ecosystem values assumed to be held by the research participants. We employed an embedded mixed methods design (Creswell 2014), where quantitative measures of ecosystem services were embedded between two qualitative questions. The first question asked participants "Would you like to tell me a story about the lagoon?" and the second qualitative question asked "After this exercise, is there another story you thought of that you would like to tell me?" When permission was granted, we audio recorded interviews. Regardless of whether or not interviews were recorded, detailed notes were taken on how the interviewee engaged with the materials, questions they had or comments they made while conducting the interview, the order in which they ranked the ecosystem services, and other details of the interview process. All interviews recorded in French were fully translated and transcribed. Interviews in Tahitian were conducted with the aid of a translator, with notes summarizing responses taken during the interview. Informed consent was read to each participant in their language of choice and either verbal or signed consent was obtained prior to the survey. All researchers were certified in CITI ethics training and this research was approved under San Diego State University IRB Board (IRB\#1476089 and \#2395104).

To quantify participant's values associated with each ecosystem service we used a photo elicitation method, which we adapted from Hicks et al. (2013). In their methodology, respondents were shown eight photos, each representing an ecosystem good or service, and were asked to (1) rank the service according to importance, and (2) to rate the services by distributing 100 points across them to show where they want improvements. In our study, we asked respondents to distribute 100 points represented by small seashells across 11 photos representing various ecosystem services and in so doing to demonstrate which ecosystem services were more important. All but the photos for education (France Info, http://la lere.francetvinfo.fr/polynesie/2013/08/14/ce-ne-serapas-une-rentree-comme-les-autres-1-ecole-maharepa-de-moorea-55605. $\underline{\mathrm{html}}$ ) and sense of place (Viola Moorea, http://www.voilamoorea. com/?lang=en\#Galerie) were taken on Moorea by our team.

Between 2014 and 2015 our team conducted 351 household surveys in Moorea, covering topics including fishing practices and perceptions of marine health and governance, among others. Responses to these surveys provided us with insights into ways that Mooreans use, value, and perceive the marine environment, which in turn informed our selection of ecosystem services to include in this research. The services we selected, included seven cultural values (bequest, cultural heritage, economic gain, education, sense of place, recreation, and tourism), two regulating services (coastal protection and sanitation), one supporting service (habitat), and one provisioning service (subsistence fishery; Fig. 2). In our analysis, we distinguish between cultural services and what we refer to as ecological services, including regulating, supporting, and provisioning services. Our research primarily focused on cultural services, but we also chose services from other categories that we thought would be salient on Moorea given our prior fieldwork. Two Moorean research partners vetted the photo cards and the definitions of the services we selected, ensuring that the photos selected were suitable and that the definitions were relevant and clear. The name of each service was written on the front of the photo with definitions written on the back. We explained to each participant that definitions were on the photos and allowed them to read the descriptions as they chose. If they appeared confused by an ecosystem service, we would read the definition to them and offer further explanation as needed, while also documenting these engagements. In addition, we collected 11 social attributes about each participant to explore how demographic characteristics influence a respondent's valuations (Table 1).

Table 1. Social attribute information collected for each survey respondent.

\begin{tabular}{|c|c|}
\hline Variable & Definition \\
\hline Age & Age of Participant \\
\hline Country & $\begin{array}{l}\text { What island or country the participant is from or } \\
\text { immigrated from. }\end{array}$ \\
\hline District & $\begin{array}{l}\text { District where participant lives, or in the case of } \\
\text { scientists, where their research station is located. }\end{array}$ \\
\hline Eats Fish & Whether or not the participant eats fish \\
\hline Gender & The gender of the participant. \\
\hline Goes Fishing & $\begin{array}{l}\text { Whether or not the participant goes fishing. If they } \\
\text { fished in the past, but do not currently, this question was } \\
\text { answered as no. }\end{array}$ \\
\hline Level of & The highest level of education the participant has \\
\hline School & achieved. \\
\hline Lived in & The length of time that the participant has lived in \\
\hline Moorea & Moorea. \\
\hline Profession & $\begin{array}{l}\text { The profession of an individual respondent. Defined as: } \\
\text { General Population (any employment status), } \\
\text { Professional Fisher (fishers who sell fish), Scientist (Full } \\
\text { Professors, PhD Students, Post-Doctoral Researchers, } \\
\text { and Technicians working in Moorea), or Tourism } \\
\text { Operator (owning or working in a tourism business). }\end{array}$ \\
\hline Religion & The religion of the participant \\
\hline Sells Fish & Whether or not the participant sells fish that they catch. \\
\hline
\end{tabular}

In the second component of our research design, we assumed that any of the participants' difficulties with the survey were not moments to immediately intervene and guide them toward a proper methodological protocol, but rather we viewed these as comments about the research that should be documented. Thus we carefully documented their concerns, moments of puzzlement, or misgivings with the survey structure through recordings, notetaking, and asking clarifying questions about respondents' thought processes during the interview process. In other words, we treated respondents as more than participants, but as interlocutors. We viewed them as contributing to our research beyond simply participating in a study as subjects, but as rendering legible any conceptual and ontological commitments of the survey and the ES framework more generally. Rather than assuming that the survey tool was a neutral conduit through which ecosystem services could be valued, we remained attentive to identifying its possible effects on our research outcomes.

The third component of our research design was to have survey participants evaluate the survey. To do this we asked respondents three open-ended questions about the survey's ability to capture their experiences, thoughts, and/or feelings of the marine environment. We also asked participants if there were any ecosystem services that were either missing from or that should be changed on the survey. 
Fig. 2. Photo cards and definitions of ecosystem services that were assigned points to demonstrate their importance by respondents from four profession groups.

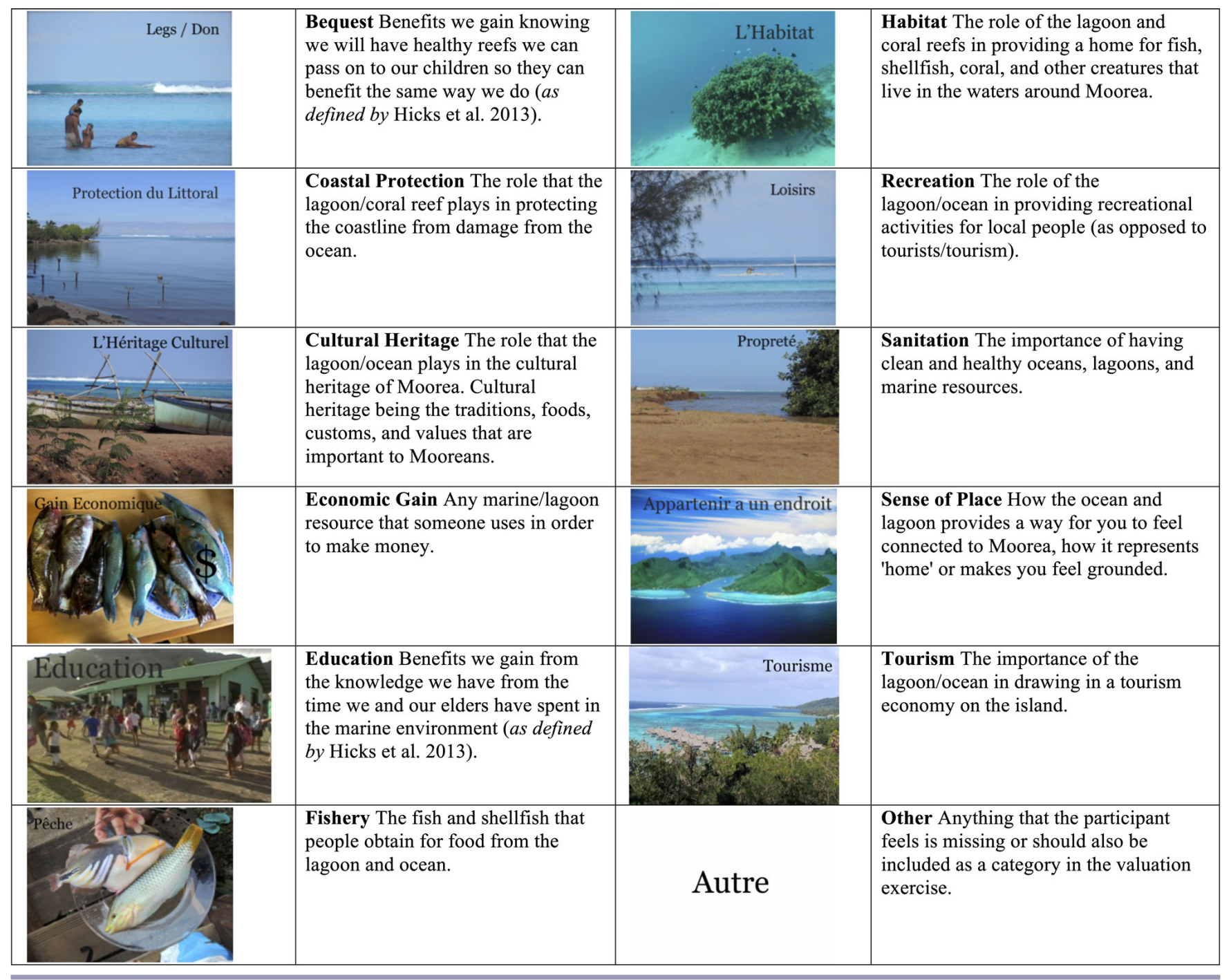

In analyzing the point assignments for the photo elicitation portion of the survey, we first used descriptive statistics to find the average importance scores for each service as ranked by each profession group. We used Kruskal-Wallis tests to identify which ecosystem services had statistically significant differences in scores between groups. Post-hoc Dunn tests, with a Bonferroni adjustment, identified between which profession groups significant differences occurred.

We coded our qualitative data for themes and patterns. Our codes include the services that were measured in the survey, i.e., "bequest" or "cultural heritage," as well as in-vivo and descriptive codes (Saldaña 2013). Simultaneous coding (Saldaña 2013) was occasionally used when interviewee responses converged on two codes at the same time, for example, if two services were mentioned simultaneously, i.e., habitat and fishery being discussed in a single statement.

\section{ECOSYSTEM SERVICES VALUATIONS AND INTERACTIONS}

Differences in ES scores by profession

In the average ranking scores, habitat ranked highest for both the general population and scientist groups (Fig. 3). Subsistence fishery was ranked highest by the professional fisher group. For both the general population and the fisher groups, economic gain was ranked as the second most important service. Education and cultural heritage were ranked as the first and second most important services, respectively, by tourism operators, though cultural heritage was ranked as the sixth or seventh most important by the other profession groups. Education was ranked in the top five services by all groups. Scientist's top four most important ecosystem services were the supporting, regulating, and provisioning services, the seven cultural values measured being ranked below these more ecological categories. For all four groups, the services tourism and recreation were ranked in the lowest three categories. 
Fig. 3. Average scores of ecosystem services by profession group.

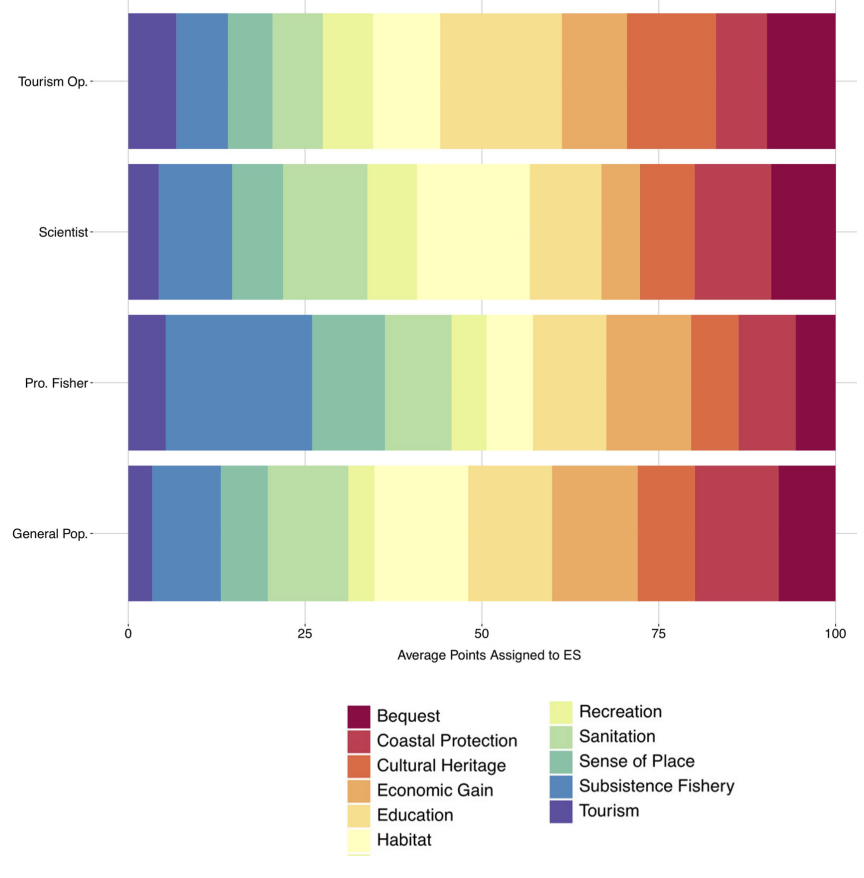

Kruskal-Wallis tests identified significant differences between groups for four services, including: habitat $(\mathrm{K}(3)=12.34, \mathrm{p}=$ $0.006)$, recreation $(\mathrm{K}(3)=11.23, \mathrm{p}=0.010)$, subsistence fishery $(\mathrm{K}(3)=10.381, \mathrm{p}=0.015)$, and tourism $(\mathrm{K}(3)=9.25, \mathrm{p}=0.026)$. Post-hoc Dunn tests identified between which groups differences occurred, which are represented in box plots (Fig. 4). For habitat significant differences occurred between fishers and scientists ( $\mathrm{p}$ $=0.002, z=-3.40)$. For recreation, the general population and scientists' rankings were significantly different $(\mathrm{p}=0.008, \mathrm{z}$ $=-3.01$ ). The ranking of the service subsistence fishery differed between professional fishers and the general population $(\mathrm{p}=$ $0.016, z=2.79)$ and between professional fishers and tourism operators $(p=0.017, z=2.76)$. Finally, tourism had significant differences in rankings between the general population and tourism operators $(\mathrm{p}=0.015, \mathrm{z}=-2.81)$. The services bequest, coastal protection, cultural heritage, economic gain, education, sanitation, and sense of place did not have significant differences in group rankings.

\section{Fishing and ES categories}

Subsistence fishery was the only service that differed significantly between more than two groups. Moorea has a thriving coral reef fishery. Eating fresh reef fish and fishing are important to Tahitian's daily lives, especially for those who may lack other means to earn a living. As one professional fisher told us, "... subsistence fishery is my grandmother - she feeds you ..." (June 2016). Or as a man from the general population commented, "The fish, the crustaceans, the offerings of the sea are what keeps people alive here"(June 2016). Equating fisheries with grandmothers and describing the sea as "offering" fish exemplify a certain ordering of human relations with other beings, an ordering that levels the ocean and people as agents in mutual relationships. This ordering was not adequately captured by the photo elicitation exercise and only arose through our conversations surrounding the survey process itself.

Fig. 4. Average rankings with standard deviations of ecosystem services identified as having significant between-group differences by Kruskal-Wallis and post-hoc Dunn tests.
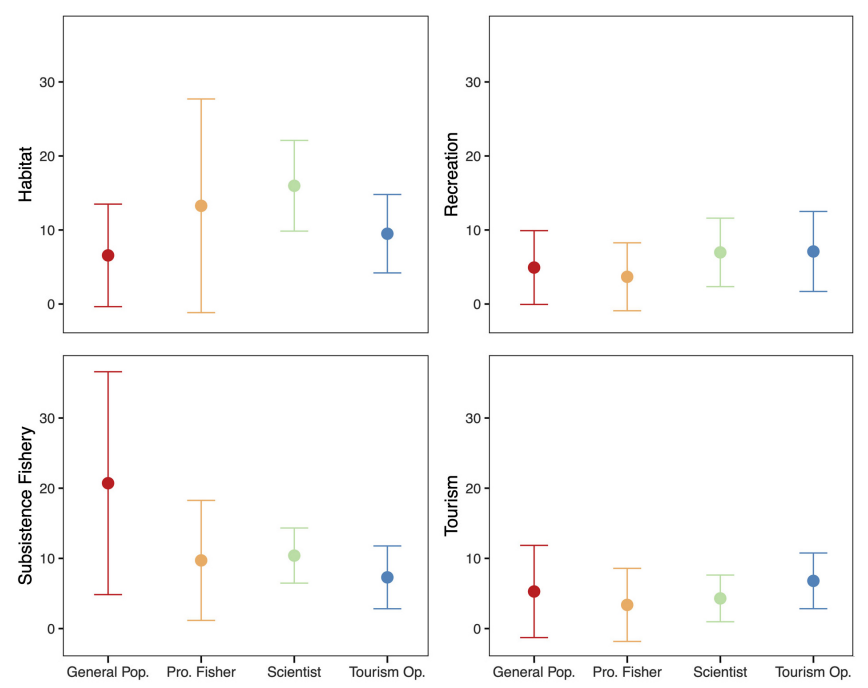

In our view, the photo elicitation process embodies the ontological commitments of the ES framework. Although the photo elicitation process seeks to elicit values about ecosystem services such as subsistence fishery, for Tahitian respondents, this category carves up the world in ways that do not correspond to their statements about the sea and fishery. That is, Tahitians discuss the sea and fishery as entities that are more than mere objects to be harvested or passive containers upon which humans bestow meaning and act out their lives. Rather, Islander's conception of marine habitats is more akin to what Jane Bennett calls "vibrant matter," those other-than-human entities that "act as quasi agents or forces with trajectories, propensities, or tendencies of their own" (Bennett 2010:viii). Thus, the sea and fishery respond to and interact with Tahitians in dynamic ways and in relationships that index kinship, as grandmothers. In addition to having forces or propensities to act, fishing also tends to be a morally bound activity in the Pacific. For instance, in the Philippines, it is described as a "right-to-survive" (Segi 2013). Nevertheless, the MEA treats subsistence fishery as a provisioning resource, a category that relies on a purportedly universal discontinuity between fish and the ocean and any moral or agentive qualities of these beings. A subsistence fishery as a provisioning service is something that is acted upon by humans; it is one of the benefits humans obtain from nature, rather than something through which fish and the ocean respond to, interact with, and hold kin relationships with fishers.

Professional Fishers ranked subsistence fishery and economic gain as their top two ranked services. One could interpret this as Moorean fishers being more concerned with cultural services than ecological services. Particularly in comparison to scientists who 
ranked habitat the highest. Four of the top five services ranked by scientists were ecological, while for fishers and tourism operators four of their top five ranked services were cultural. But as noted above, for Tahitians, fisheries are as much cultural as ecological, thus we cannot, a priori, assume that the category of subsistence fishery is solely an instrumental or utilitarian value, but an activity that constitutes relationships and responsibilities.

\section{Scientists and ecological values}

It is perhaps unsurprising that scientists ranked habitat highest given that the scientists we interviewed were primarily trained in marine biology and ecology. Yet, when we asked them to talk about their relationship with the lagoon they sometimes mixed cultural and ecological categories, which the ES framework attempts to separate. On the one hand they discussed ecosystem functions of Moorea's coral reefs as if the marine environment was simply an object useful for generating information.

I think one of the things that Moorea does is that it is a model system for preserving ecosystem functions that can be applied in other places. So that, it is important in the transfer of information out of the local situation ... it is scalable and transferable information (July 2016).

At the same time they spoke of nostalgic memories of being in coral reefs, sometimes for the first time, and their bodily experiences of drifting through crystal clear water. Such as this story detailing a rare encounter with a dolphin in the lagoon: “... I was able to play in the water with the dolphin and I remember it was copying me. As I would turn around it would turn around too. So that was pretty special and it was in the middle of the blue" (July 2016). Thus, scientists' descriptions of the marine environment in some ways parallel those of Tahitians in that they did not necessarily describe the environment and the beings inhabiting it as separate from the affective experiences of being human; rather through this experience the dolphin and the person were, at least momentarily, entangled.

\section{Economic gain and ecological degradation}

There was congruence between the scientist and fisher groups over economic gain. For both groups, marine-centric activities focused around economic gain were described as corrosive to the health of the marine ecosystem. For example, one fisher who relies on net fishing for income described the money he made from selling fish as "dirty money." Many Tahitians also described respect for the marine environment and economic gain as mutually exclusive. As one woman from the general population explained: "Because people don't respect the lagoon, the sea is for sale. It is dead. It is destroyed" (June 2016). For scientists as well, economic gain was viewed as key driver of ecological degradation: "When I first got here [to Moorea] I would have said it's [the reef] trashed, it's over, too much [negative environmental impact] from the hotels, and too many tourists anchoring boats and riding jet-skis, and too many fishermen smacking the reef apart to get at Tridacna [Pacific giant clam]" (July 2016). Thus, our open-ended interviews suggest that profession groups shared concerns and perspectives about marine health while there was also variation in how groups valued the ecosystem services we presented to them.

However, there were some differences between how scientists described environmental degradation versus Tahitians, though each group commonly mentioned climate change, ocean bleaching, and pollution. In addition to these topics, Moorea's scientists also discussed Acanthaster planci (crown-of-thorns starfish) outbreaks, loss of coral reef resilience, or how various ecological and anthropogenic processes link together to create environmental change. This scientist's description, for example, details why she focused on the ES habitat:

That then influences things like fisheslfishery... and then
how the environment responds to human variation and
human induced stresses and then obviously how that
influences and is superimposed on a background of
environmental change from global changes to the
environment ... which of course is going to influence
things like the protection of services because of sea level
rise (July 2016).

Whereas scientists often discussed ecological and biological stressors and to a lesser extent human induced degradation, Tahitians often explicitly linked degradation to human activities and to environmental protection. "... but the biggest predator is humans. It is humans who are dangerous not the sharks" (June 2016). Or as another respondent said, "Because the coral is dying and when the coral dies, the good things that the ocean makes will be no more. The coral is the habitat of the fish. They live in the coral. We need to come back to the protection of the lagoon" (June 2016). Tahitians discussed environmental degradation in tandem with the importance of protecting the marine environment. Often for Tahitians, protection was linked to the idea of respect for the lagoon and how social changes have led to a lack of respect, contributing to current marine degradation.

\section{The survey in action}

The photo elicitation method we employed to assess ecosystem services is a common method, sometimes called photointerviewing, both within the ecosystem services literature and the social sciences more generally (Collier and Collier 1986). The basic assumption of photo elicitation is that a researcher can assign values, in this case ecosystem services, to photos as a means to universalize demarcated ecosystem services across different social groups. As described by Hicks et al. (2013), respondents need to be coached in order to "establish a common understanding" about the pre-assigned meaning of the photographs (p. 1447). Rather than assuming that this process of coaching and assigning values to photographs was unimportant, we viewed the administration of the survey and our respondents' interactions with it as within the frame of analysis and as a topic of inquiry. Our approach exemplifies active reflexivity (Law 2004, Mason 2017). In much social science research, when respondents seem not to follow the pre-established protocol, researchers assume that this is a methodological problem of execution. We maintained a reflexive stance toward problems and examined them as potential instances where the principals and assumptions of the ES framework are incongruent with our respondents' understandings.

As we administered the survey we noted on numerous occasions how Tahitian respondents in particular were more reliant on and reactive to the places and things depicted in the photos themselves rather than the representations of ecosystem services we imposed on the photos. Upon laying out the photo for tourism, which features overwater bungalows on Moorea's North Shore, a Tahitian respondent commented with disgust, "The hotels, 
ehhh!" and later stated "Tourism is a big problem. It creates marine pollution" (June 2016). In particular, the sanitation photo elicited many stories from Tahitian and non-Tahitian participants alike, because it shows, in part, an eroded seaside area in southern Haapiti. Responses were sometimes simple statements like this response from a Tahitian fisher: "[There is] lots of food there, lots of crabs" (June 2016). Or, at other times, longer stories about the space like with this long-time American tourism operator: "This is right over by your house, isn't it?" (Author response: "Yeah"). "That is a disaster ... there are three spots like that on the island where they kind of promised a bunch of stuff and it ended up just being - it is different than that now. They've kind of put stones there as you can see, but it's ... That is supposed to be a park for children, that is what it's made for, but here is what happened ..." (July 2016). This respondent went on to detail governmental and funding failings that led to the area being in the degraded state featured in the photo. Thus, although we asked respondents to value the services that are represented by the photos, they often reacted to the images in the photos.

The recognition of places and things featured in the photos at times led Tahitian respondents to rank the photos rather than the services that they purportedly represented. One respondent, when seeing the image for sense of place stated "Papetoai is in the image, I want to give points to Papetoai" (June 2016). We explained to him, again, how the photos were intended to represent the stated services and we noted that he started to value the pictures differently. However, at the end as we started to count the shells, despite us having explained that we would do this in the beginning of the survey, he removed shells from habitat and added them to economic gain. Another Tahitian looked at the photo for tourism and gave it zero seashell points, explaining "This is not for fishing. You take a boat to go fishing. If you do not come back with any fish then it is a waste of time to go at all" (June 2016). After completing his first round of point assignments, a Tahitian tourism operator who still had points left decided to add points to habitat because "... I think the island is beautiful here, I am going to do the coral one" (July 2016).

We interpret the "difficulties" respondents had with correctly following the survey protocol not simply as a methodological issue but rather an indication of how ES research and the photo elicitation method are grounded in similar presuppositions about what aspects of reality are contingent and what aspects are sturdy. The photo elicitation method assumes an image of the shoreline can seamlessly, without transformation, be re-read as a universally recognized and sturdy category, e.g., habitat, coastal protection, etc. Yet when the respondents were shown an image of their shoreline, this assumption was cast into doubt. This mirrors the presumption of ES research that values are contingent, interchangeable, and attachable, while ecosystem services are sturdy and universally identifiable. The difficulties respondents displayed was not that they misunderstood the protocol, but rather it indexes a critical incongruence between respondents' understandings of their environments and how environments are construed in both the photo elicitation method and ES research. In particular, Tahitians sense of place tends to blur domains that the ES framework separates, such as the spiritual from the physical, and they do not, without the researcher's encouragement, immediately interpret the images as a universal category radically detached from its history of lived or intergenerationally transmitted activity. Ample evidence from across the Pacific suggests that human and other-than-human interrelatings involve assemblages of spiritual, physical, and biological entities that cannot be neatly carved into the cultural and biological domains of the ES framework (Ward and Kingdon 1995, Lauer and Aswani 2009, Bambridge 2012). As Hviding notes "For the inhabitants of Oceania, coconuts and other living things that to outsiders might seem insignificant in terms of importance are by no means small and simple. They remain large in terms of their importance for the continuity of everyday lives... and they underpin ... knowledges of nature in Oceania" (Hviding 2003:271).

\section{STAKEHOLDER EVALUATIONS OF THE SURVEY}

Respondents from all of the profession groups expressed their approval of the ecosystem services we selected for valuation in our survey. As one scientist stated "It is pretty good in terms of covering different aspects. The main aspect is trying to cover the different usages and services we get from the environment and it covers both the social and ecological aspects of the reef" (July 2016). Another scientist, in a more personal sentiment said the services we selected basically articulated all of her motivations for becoming a marine biologist. An American tourism operator who has lived in Moorea for nearly 40 years, claimed that the exercise discussed “... the real life in French Polynesia” (July 2016). A woman from the general population explained how through the survey she was able to express her values: "Because first I prioritized my culture. Second, respecting the ocean. Third, education for my children. I was able to show my values through this exercise - how I think about these issues"(June 2016). Another man, who was a professional fisher in the past and who still goes fishing furthered this woman's sentiment, suggesting that the exercise provided a model for educating children to create good lives: "Because all of this is how you guide your child to build their future - [it is] good for their life in the future" (June 2016). Overall, there was high agreement across profession groups that services we selected for valuation were relevant and meaningful.

\section{Tahitian's evaluations}

Although participants were largely satisfied with the valuation survey categories, Tahitians' responses to the survey evaluation questions discussed certain entities in ways that do not fit neatly into the ES framework. For example, Tahitians repeatedly explained how the ocean had agency, as did this respondent when explaining that the survey both did and did not reflect his experiences, thoughts, and/or feelings about marine environment: "... first of all I am a waterman. I've seen the sea angry, calm, its mood. I've seen the lagoon, the fish, how they react" (July 2016). As expressed, the ocean is conceived of as agential and moody, descriptions that could be interpreted as culturally specific mental schema shaping Tahitian's perception of the natural world. Yet this is one case among many where Tahitians describe the ocean and fish not as passive receptors of human actions or mental schemes nor as entities that exist independent of human agency. Instead, Tahitians describe themselves and the lagoon, ocean, and land as intimately and inextricably entangled. As a professional fisher stated, "I live this. I live the land and ocean. Yes, I know the fishery ... My ancestors lived this way too - the land and the ocean. My child lives this too" (June 2016). This point was reiterated by another member of the general population: "Here 
sense of place is true. We live in the water, this is not evident, this is true. We need the land to live, but the water for the fish. The fishery, is a way for us to feed ourselves. We need underwater things to live, but we are lucky to live on land also" (June 2016).

Most ES research provides explanations that render some types of human and other-than-human relations more legible than others. For example, when Tahitians say "I live the land and ocean" and describe themselves as intermixed with the land and sea, this possibility is silently deleted by the ES framework because humans and the ocean exist only as bounded entities that are ontologically distinct from each other. Instead of adhering explicitly to how informants describe the world, the ES framework converts their understandings into categories legible to ES inquiry. In this process of translation, ES researchers delete away a land-sea-fisher category and replace it with a description that assumes that humans can only place value on the land and sea, rather than being the land and sea. Through this translation, ES research subtly distributes agency to humans and renders the biophysical world as an inert receiver of culture, meaning, or symbolism. If the goal of much ES research is to understand how people value their environments, these subtle, yet critical, translations must be treated as a focus of inquiry rather than disregarded through the assumption of the universality of certain ontological commitments.

\section{Scientist's evaluations}

Moorea's scientists, on the other hand, emphasized different issues with the ES survey. Despite scientists agreeing that the ES survey did hold relevance, they further explicated that they often did not experience the values represented in the photos as they conducted their field research in the marine environment. They described the experience of conducting research as a fundamentally different modality than recreating or just swimming through the lagoon. As one researcher noted, "You know, when I am in the lagoon I am often experiencing work because that is what I often do in the lagoon. So although I may think of some of these things, most of the time when I am in the lagoon it is for scientific research and so I am working" (July 2016). Scientific fieldwork, for this scientist, was a specific mode of action where personal values were not operative.

In another expression of this sentiment, scientists, when asked about how the survey captured their relationships to the lagoon, or when asked if anything was missing, would often contrast their scientific experiences with personal experiences. A PhD student, for example, when asked this question, clarified that she would answer differently if she were to comment on her scientific versus her personal relationship with the lagoon: “... my interactions with the lagoon are divided into scientific experiences and personal experiences. The personal experiences, yes. I guess another category you could add would be ... usefulness for testing scientific theory" (July 2016). These statements suggest that scientists actively impose a discontinuity between their work activities in the lagoon on the one hand and their experiences recreating or relaxing in the lagoon on the other. This partitioning of experience was so important to Moorea's scientists that roughly half of them suggested science be added as a distinct value category to our ES survey.

A number of scientists expressed this idea in a different register when they described how their scientific training shaped their relationship to and experience in the lagoon. A scientist explained why science was an important value to enumerate in the photo elicitation process: "It is mostly there, but being a scientist I have a proportion of science in my background and that is what I do and that is kind of part of who I am and so there is this science component that is not in this" (July 2016). These scientists value scientific research as a cultivated access mode that frames their experience with the marine ecosystem. The value they describe is similar to what science studies scholars call the "view from nowhere" (Haraway 1988) and is premised on the notion that all other positions, except the scientific mode of inquiry, are distorted by subjectivity. Similarly, scientists assume that human experience and human values are ontologically distinct yet they recognize that "in reality" experience and values intermix and that their quest for purification is not achievable in practice.

\section{Because we humans always want to put a value to things and in order to put values into very clear boxes we create all these different categories that in reality, while they are linked to what we experience, they are not exactly the same thing ... The truth is that in reality it is very hard to disassociate certain things (July 2016).}

When we place how Moorean scientists discussed the ES survey's weaknesses next to the issues raised by Tahitians we note a critical difference. Moorean scientists, for their part, value two discontinuities: the dichotomy between their personal and scientific experience and the dichotomy between their ideas about the world and reality itself, whereas Tahitians appear to value continuity and the intermixing between humans and other beings and entities. Ironically, the world that Tahitians compose is precisely the intermixed one that scientists admit is the real "reality," but which they do not allow themselves to fully commit to, on the pretense that proper scientific work generates a valuefree representation of the biophysical world.

\section{TENSIONS OF THE ELICITED}

To summarize and synthesize our findings, we focus on three tensions that emerged through our reflexive approach. These include, (a) a distinction made between subsistence fishing as a positive activity and economic gain as a degrading activity by Moorea's professional fishers, (b) a tension between how scientists and fishers valued different services as evidenced in the photo elicitation results, and (c) a tension between the assumption that assigning ecosystem services to photos was a transparent method and the way that respondents interpreted photos. In the following, we discuss the relation of each tension to nature-culture dualism and make the argument that ES research should be treated as a situated practice.

First, we note how Moorea's fishers made a sharp distinction between subsistence fishing and economic gain. This tension between subsistence activities and economic gain mirrors what has been reported by ES researchers in other contexts in the Global South. In Southern Guyana, for example, Indigenous peoples ranked the subsistence values of plants as more important than logging values (Shah and Cummings 2018). Similarly, research conducted in Bangladesh found that research participants rely on materials provided by provisioning services more for subsistence than for cash purposes (Ahammad et al. 2019). Yet, researchers working in this domain also note the potential tensions between extraction activities for either 
subsistence or monetary purposes and ecosystem health (Ahammad et al. 2019, Yadav et al. 2019). Indeed, the profession groups we interviewed expressed interest in harvesting coral reef fish, but noted that fishing motivated solely by economic gain typically leads to environmental degradation.

There were differences, however, between fishers' and scientists' descriptions of degradation. Fishers described environmental degradation as the joint demise of the lagoon and of their moral fabric, articulating how respect involves both respecting the Tahitian way of life and respecting and being responsible for the lagoon. These descriptions assumed that the lagoon was a composite of human and other-than-human relations. In contrast, scientists tended to describe ecological degradation as a process where human activities impact the lagoon, which presupposes that the world is not a composite of human and other-than-human entities, but instead, that there is an objectified nature upon which humans interfere. Tahitian's descriptions of the lagoon as a composite of human and other-than-human relations may not have been legible without the use of ethnographic methods, a research method for which some relational value researchers also advocate (i.e., Saxena et al. 2018). Indeed, ethnographic and in-depth qualitative methods provide another mode to explore peoples' relationships to other-thanhumans as was demonstrated in this research. Nevertheless, any method has effects and reflexivity necessitates that researchers be cognizant of what ES research produces and possibly displaces without subscribing to certain already identified framings such as nature-culture dualism.

Second, the photo elicitation exercise provided numeric evidence of a tension between scientists and fishers, each valuing different services, which could lead to disagreements or conflicts in management decision making and priorities under a traditional ES framework. Scientists on Moorea ranked habitat as their most important ES while fishers ranked subsistence fishery highest. The finding that scientists and fishers ranked services differently, is consistent with Hicks et al.'s (2013) research where fishers were more likely to prioritize fishery services, while scientists were more likely to prioritize coastal protection values. In explaining this variation, Hicks et al. state that "... the synergies and tradeoffs that emerge between stakeholders' ecosystem service priorities may be the result of differences in their social characteristics, experiences, and conceptual understandings of the system; all attributes that if understood can be navigated" (p. 1451). What this statement suggests is that the variability in how people value ecosystems is wholly a human or cultural process and that the role of the ES analyst is to describe the cultural, psychological, or social differences that may vary by individual, stakeholder group, or some other important demographic or cultural characteristic.

Indeed, various ecosystem services assessments seek to identify the ways that valuations vary by demographic characteristics. For example, finding that results vary by age, place of origin, or gender (Oteros-Rozas et al. 2014); by the income that participants derived from various ecosystem services they use and live with (Tadesse et al. 2014); or by ethnicity and livelihood strategy (Cuni-Sanchez et al. 2019). However, what is left unnavigated in much of the ecosystems services literature, and within Hicks et al.'s statement quoted above, is that the ecosystems services themselves are assumed to be pre-determined, immutable, and self-evident entities. Put differently, the ES framework readily acknowledges variability in cultural forms, yet it simultaneously assumes the solidity, or non-variability, of "natural" domains. Building on this variable (culture) non-variable (nature) dichotomy, the objective of the ES analyst then becomes to make sense of the infinitely variable cultural forms projected onto the biophysical world. In turn, this implicit commitment occludes ES researchers from recognizing how the assumption of non-variability privileges some descriptions of the biophysical world, while overlooking other modes of understanding and other orderings of human and other-than-human relations. Relational values indeed are an attempt to address this by broadening ES categories from intrinsic and utilitarian values to all types of relationships (Chan et al. 2018, Himes and Muraca 2018). However, rather than questioning the ontological assumptions of the ES framework itself, relational values shift the focus to the relationship between an ecosystem value and a person or human collective, thus maintaining a commitment to a nature-culture dichotomy (Fig. 5).

Fig. 5. Conventional ecosystem services (ES) research assumes that values are superimposed on ES. Based on this schema the researcher stands above the world as she documents and compares different stakeholders' values about nature.

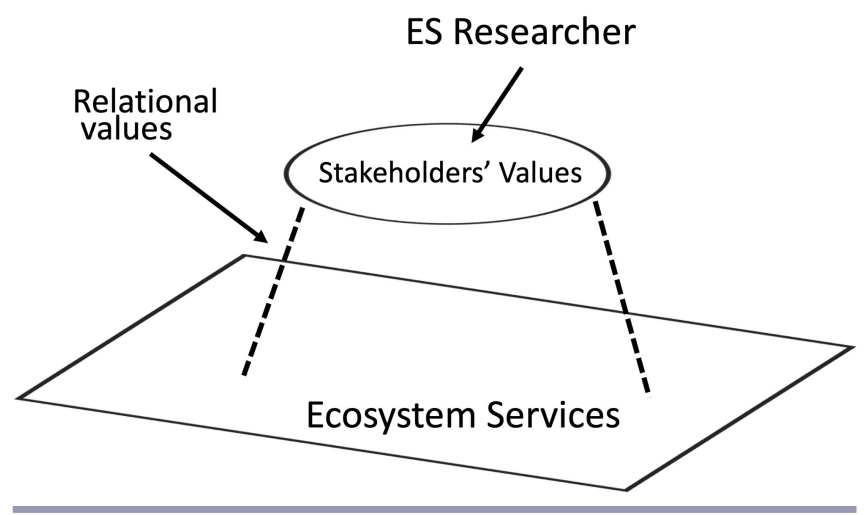

In our reflexive mode of inquiry, we attempted to register and document the effects a conventional ES approach has on producing knowledge while also creating a space for different ways of ordering human and other-than-human relationships to become legible. For example, Tahitian respondents discussed themselves and the land and sea as co-creating and contributing to a human and other-than-human collective. Rather than assuming that these descriptions are examples of Tahitians placing their cultural values on the biophysical world, we remained attentive to how and in what way this world is composed. Interestingly, Moorea's scientists lend credence to the notion that the world tends to be a blurred mixture of social values and natural systems, despite them distinguishing between social and ecological domains as they conduct scientific activities in the lagoon.

In some ways, our results parallel Pascua et al.'s (2017) work among Indigenous Hawaiians that used a participatory methodology and asked Hawaiians about their relationships with the environment. In this study, participants did not distinguish between ecosystem services and values. Instead, they proposed 
four Hawaiian concepts within which various other phenomena are organized. These concepts included: Ike (knowledge), Mana (spirituality), Pilina Kanaka (social interactions), and Ola Mau (physical and mental wellness). The authors compared these Hawaiian concepts to conventional ES categories, an approach that is a step toward circumventing the ES framework's displacement of other ways of ordering human and other-thanhuman relationships that do not ascribe to the nature-culture dichotomy.

Indeed, there has been a movement toward accounting for other forms of engendering human and other-than-human relations within the ES literature. Researchers have used approaches like Pascua et al.'s (2017) for collaboratively identifying values, while others have examined differences between how respondents describe values and the ways in which values are articulated with in the ES framework (Stålhammar and Pedersen 2017). Kenter et al. (2016) emphasize the role of deliberation in ecosystem service research in order to identify shared values and to integrate multiple types of knowledge and ontologies. They note that values, ethics, and social justice are not necessarily agreed upon categories and thus should be deliberated rather than imposed (Kenter et al. 2016). Our reflexive approach, we argue, is more open to multiple ways of knowing than conventional ES research and can lead to a wider diversity of applications. Rather than assuming that ES research produces actionable knowledge that can unequivocally direct resource management schemes, we envision ES research as a means to register the possible alternative ways of belonging with the world and to deliberate their potential outcomes.

A third notable tension that arose during our research was the assumption that assigning ecosystem services to photos was a transparent method. Following conventional ES research methods we designed the photo elicitation exercise as if the specific locales or entities depicted in the photos were universally recognized conceptual categories that could be assigned to services. However, many Tahitian respondents assigned points to the photos based on whether the locations depicted in the images had specific histories with positive or negative outcomes. In other words, Tahitian respondents tended to value the content of the images instead of the services we assigned to them. Rather than assuming that our respondents were not understanding our research protocol, we suggest that this disconnect reveals the modernist (sensu Latour 1991, Descola 2013) assumption that there is a fundamental discontinuity between how people value and the environments in which they live. Mooreans focused not on these discontinuities but instead relied on a different conceptual resource when they interpreted the photos and when they evaluated the ES survey. They assumed a continuity or intermeshing between themselves, landscapes, and seascapes and that the images of their island presented in the survey were inseparable from the legacies, histories, and values of the people who have inhabited these areas. In order for Moorean respondents to adhere to the ES framework they had to shift the ontological status of the photos and assume they were generic and universal categories upon which to project values. To participate in the photo elicitation exercise "correctly", Moorean participants had to ignore the histories and legacies of a particular landscape or seascape. In other words, Mooreans had to deny what the scientists described as "reality" and were asked to mimic our method of deletion and grasp the locations and entities in the photos as inert backdrops to the values superimposed over them.

These subtle conceptual issues and other unarticulated commitments became legible while we conducted the survey and documented it in action. Our approach, inspired by science studies scholars, was to treat the ES survey as a knowledge acquisition device that contributes to our data rather than simply producing it transparently (Law 2004). Through observing the survey in action we are able to empirically document its effects. ES research might be improved if we continue to seek methods that assess both what it is that ES research formally measures and what the methodology and conceptual framework of ES may produce in the practice of research.

\section{CONCLUSION}

In sum, when participants in ES research agree that the imposed categories are relevant to their lives, we should not assume that the research transparently captures stakeholders' ways of knowing and being. Like all frameworks and methods, ES research is not a neutral conduit by which to illuminate people's values. Indeed, our research demonstrates that coupling ethnographic and reflexive methods enables insights into the ways in which ES research may reveal and occlude certain orderings of human and other-than-human relationships. We therefore argue that ES research is best executed as a situated practice, where values are not simply extracted from participants but are collaboratively identified, contested, and rendered legible by both the researcher and participants. Although the relational values framework is a step toward this direction, it still operates as if nature is a domain of reality radically distinct from the values imposed on it and thus limits its explanatory potential. A fully relational framework would acknowledge that relations and objects are co-constitutive and that other objects and relations are salient possibilities.

Rather than assuming that ES research is a method that only holds a mirror up to reality and describes it, we conceived of our research as also a process of entering into relations and processes "so as to bring them into the field of our awareness" (Ingold 2019:659). This is especially pertinent for ES research conducted in non-Western contexts of the Global South, where basic categories of Western thought such as culture and nature or subject and object do not necessarily hold salience. Thus, if ES research aspires to be a productive boundary object that engenders more sustainable human and other-than-human relations, we suggest that it be applied reflexively and openly so that all ways of knowing and modes of understanding are given space. Rather than providing the answers for effective environmental management, ES research is well positioned to generate an array of new understandings, types of knowledge, and possibilities for social-ecological futures that reshape both stakeholders and the researchers' notions of environmental stewardship. To succeed in this goal, ES research should pay attention to what is produced in its acts of translation. For it is through an inclusive process of inquiry that we have a chance to forge collective courses of action that simultaneously protect biodiversity and embrace differences rather than dismiss them (Turnhout et al. 2013). 
Responses to this article can be read online at: https://www.ecologyandsociety.org/issues/responses. php/12253

\begin{abstract}
Acknowledgments:
We thank University of California Berkeley Gump Research Station and the US NSF Moorea Coral Reef Long-Term Ecological Research project, including Ms. Hinano Murphy for logistic support. We thank T. Atger and P. Germain for help with survey design and fieldwork. Many thanks to the Social-Ecological Systems Group at The Ohio State University as well as two anonymous reviewers for their feedback on earlier drafts. We would also like to thank the IUCN for their generous support in publishing this article as part of the Special Feature. We gratefully acknowledge the support of the National Science Foundation (OCE 1325554, 1325652) and San Diego State University. This research was approved by San Diego State University IRB\#1476089 and \#2395104. Permits for fieldwork were issued by the Hautcommissariat de la République en Polynésie Française (DRRT).
\end{abstract}

\section{Data Availability:}

The ecosystem services quantitative valuation data is available upon request from the corresponding author.

\section{LITERATURE CITED}

Ahammad, R., N. Stacey, and T. C. H. Sunderland. 2019. Use and perceived importance of forest ecosystem services in rural livelihoods of Chittagong Hill Tracts, Bangladesh. Ecosystem Services 35:87-98. https://doi.org/10.1016/j.ecoser.2018.11.009

Bambridge, T. 2012. Savoirs traditionnels et biodiversité en Polynésie Française. Culture et Recherche 126:32.

Barnaud, C., and M. Antona. 2014. Deconstructing ecosystem services: uncertainties and controversies around a socially constructed concept. Geofroum 56:113-123. https://doi. org/10.1016/j.geoforum.2014.07.003

Bennett, J. 2010. Vibrant matter: a political ecology of things. Duke University Press, Durham, North Carolina, USA.

Castri, F. di. 2002. Diversification, connectivity and local empowerment for tourism sustainability in South Pacific Islands - a network from French Polynesia to Easter Island. Pages 257-284 in F. di Castri and V. Balaji, editors. Tourism, biodiversity and information. Backhuys, Leiden, The Netherlands.

Chan, K. M. A., R. K. Gould, and U. Pascual. 2018. Editorial overview: relational values: what are they, and what's the fuss about? Current Opinion in Environmental Sustainability 35:A1A7. https://doi.org/10.1016/j.cosust.2018.11.003

Chan, K. M. A., T. Satterfield, and J. Goldstein. 2012. Rethinking ecosystem services to better address and navigate cultural values. Ecological Economics 74:8-18. https://doi.org/10.1016/j. ecolecon.2011.11.011
Collier, J., and M. Collier. 1986. Visual anthropology: photography as a research method. University of New Mexico Press, Albuquerque, New Mexico, USA.

Costanza, R., R. d'Arge, R. de Groot, S. Farber, M. Grasso, B. Hannon, K. Limburg, S. Naeem, R. V. O. O’Neil, J. Paruelo, R. G. Raskin, P. Sutton, and M. van den Belt. 1997. The value of the world's ecosystem services and natural capital. Nature 387:253-260. https://doi.org/10.1038/387253a0

Creswell, J. W. 2014. Research design: qualitative, quantitative, and mixed methods approaches. Fourth edition. SAGE, Thousand Oaks, California, USA.

Cuni-Sanchez, A., A. S. K. Ngute, B. Sonké, M. N. Sainge, N. D. Burgess, J. A. Klein, and R. Marchant. 2019. The importance of livelihood strategy and ethnicity in forest ecosystem services' perceptions by local communities in north-western Cameroon. Ecosystem Services 40:101000. https://doi.org/10.1016/j.ecoser.2019.101000

Daily, G. C. 1997. Nature's services: societal dependence on natural ecosystems. Island, Washington, D.C., USA.

Daniel, T. C., A. Muhar, A. Arnberger, O. Aznar, J. W. Boyd, K. M. A. Chan, R. Costanza, T. Elmqvist, C. G. Flint, P. H. Gobster, A. Gret-Regamey, R. Lave, S. Muhar, M. Penker, R. G. Ribe, T. Schauppenlehner, T. Sikor, I. Soloviy, M. Spierenburg, K. Taczanowska, J. Tam, and A. von der Dunk. 2012. Contributions of cultural services to the ecosystem services agenda. Proceedings of the National Academy of Sciences 109(23):8812-8819. https:// doi.org/10.1073/pnas.1114773109

Descola, P. 2013. Beyond nature and culture. University of Chicago Press, Chicago, Illinois, USA.

Gould, R. K., S. C. Klain, N. M. Ardoin, T. Satterfield, U. Woodside, N. Hannahs, G. C. Daily, and K. M. Chan. 2015. A protocol for eliciting nonmaterial values through a cultural ecosystem services frame. Conservation Biology 29(2):575-586. https://doi.org/10.1111/cobi.12407

Haraway, D. 1988. Situated knowledges: the science question in feminism and the privilege of partial perspective. Feminist Studies 14(3):575-599. https://doi.org/10.2307/3178066

Hemmingham, S. 1992. France and the South Pacific: a contemporary history. University of Hawaii Press, Honolulu, Hawaii, USA.

Hicks, C. C., N. A. J. Graham, and J. E. Cinner. 2013. Synergies and tradeoffs in how managers, scientists, and fishers value coral reef ecosystem services. Global Environmental Change 23(6):14441453. https://doi.org/10.1016/j.gloenvcha.2013.07.028

Himes, A., and B. Muraca. 2018. Relational values: the key to pluralistic valuation of ecosystem services. Current Opinion in Environmental Sustainability 35:1-7. https://doi.org/10.1016/j. cosust.2018.09.005

Hirons, M., C. Comberti, and R. Dunford. 2016. Valuing cultural ecosystem services. Annual Review of Environment and Resources 41(1):545-574. https://doi.org/10.1146/annurev-environ-110615-085831

Hviding, E. 2003. Both sides of the beach: knowledges of nature in Oceania. Pages 245-275 in H. Selin, editor. Nature across 
cultures: views of nature and the environment in non-Western cultures. Kluwer Academic, Dordrecht, The Netherlands. https:// doi.org/10.1007/978-94-017-0149-5 13

Ingold, T. 2019. Art and anthropology for a sustainable world. Journal of the Royal Anthropological Institute 25(4):659-675. https://doi.org/10.1111/1467-9655.13125

Kahn, M. 2011. Tahiti beyond the postcard: power, place, and everyday life. University of Washington Press, Seattle, Washington, USA.

Kenter, J. O., R. Bryce, M. Christie, N. Cooper, N. Hockley, K. N. Irvine, I. Fazey, L. O'Brien, J. Orchard-Webb, N. Ravenscroft, C. M. Raymond, M. S. Reed, P. Tett, and V. Watson. 2016. Shared values and deliberative valuation: future directions. Ecosystem Services 21:358-371. http://dx.doi.org/10.1016/j.ecoser.2016.10.006

Kull, C. A., X. Arnauld de Sartre, and M. Castro-Larrañaga. 2015. The political ecology of ecosystem services. Geoforum 61:122-134. https://doi.org/10.1016/j.geoforum.2015.03.004

Labrosse, P., J. Ferrais, and Y. Letourneur. 2006. Assessing the sustainability of subsistence fisheries in the Pacific: the use of data on fish consumption. Ocean and Coastal Management 49 (3-4):203-221. https://doi.org/10.1016/j.ocecoaman.2006.02.006

Latour, B. 1991. We have never been modern. Harvard University Press, Cambridge, Massachusetts, USA.

Lauer, M. 2014. Calamity, kastom, and modernity: local interpretations of vulnerability in the western Pacific. Environmental Hazards 13(4):281-297. https://doi. org/10.1080/17477891.2014.921594

Lauer, M., and S. Aswani. 2009. Indigenous ecological knowledge as situated practices: understanding fishers' knowledge in the Western Solomon Islands. American Anthropologist 111 (3):317-329. https://doi.org/10.1111/j.1548-1433.2009.01135.x

Law, J. 2004. After method: mess in social science research. Routledge, London, UK. https://doi.org/10.4324/9780203481141

Leenhardt, P., M. Lauer, R. M. Moussa, S. J. Holbrook, A. Rassweiler, R. J. Schmitt, and J. Claudet. 2016. Complexities and uncertainties in transitioning small-scale coral reef fisheries. Frontiers in Marine Science 3:70. https://doi.org/10.3389/ fmars.2016.00070

Levy, R. L. 1973. Tahitians: mind and experience in the Society Islands. University of Chicago Press, Chicago, Illinois, USA.

Mason, J. 2017. Qualitative researching. Third edition. SAGE, London, UK.

Millennium Ecosystem Assessment (MEA). 2003. Ecosystems and human well-being: a framework for assessment. Island, Washington, D.C., USA.

Norgaard, R. B. 2010. Ecosystem services: from eye-opening metaphor to complexity blinder. Ecological Applications 69 (6):1219-1227. https://doi.org/10.1016/j.ecolecon.2009.11.009

Oteros-Rozas, E., B. Martín-López, J. A. González, T. Plieninger, C. A. López, and C. Montes. 2014. Socio-cultural valuation of ecosystem services in a transhumance social-ecological network.
Regional Environmental Change 14:1269-1289. https://doi. org/10.1007/s10113-013-0571-y

Pascal, N., and G. LePorte. 2015. Valeur Monétaire des ecosystèmes coralliens et associés de Moorea. CRIOBE, Moorea, Polynésie Française.

Pascua, P., H. McMillen, T. Ticktin, M. Vaughan, and K. B. Winter. 2017. Beyond services: a process and framework to incorporate cultural, genealogical, place-based, and indigenous relationships in ecosystem service assessments. Ecosystem Services 26:465-475. http://dx.doi.org/10.1016/j.ecoser.2017.03.012

Raymond, C. M., G. G. Singh, K. Benessaiah, J. R. Bernhardt, J. Levine, H. Nelson, N. J. Turner, B. Norton, J. Tam, and K. M. A. Chan. 2013. Ecosystem services and beyond: using multiple metaphors to understand human-environment relationships. BioScience 63(7):536-546. https://doi.org/10.1525/bio.2013.63.7.7

Saldaña, J. 2013. The coding manual for qualitative researchers. Third edition. SAGE, Los Angeles, California, USA.

Salvat, B., and C. Pailhe. 2002. Islands and coral reefs, population and culture, economy and tourism: world view and a case study of French Polynesia. Pages 213-31 in F. di Castri and V. Balaji, editors. Tourism, biodiversity and information Backhuys, Leiden, The Netherlands.

Saxena, A. K., D. Chatti, K. Overstreet, and M. R. Dove. 2018. From moral ecology to diverse ontologies: relational values in human ecological research, past and present. Current Opinion in Environmental Sustainability 35:54-60. https://doi.org/10.1016/j. cosust.2018.10.021

Schröter, M., E. H. van der Zanden, A. P. E. van Oudenhoven, R. P. Remme, H. M. Serna-Chavez, R. S. de Groot, and P. Opdam. 2014. Ecosystem services as a contested concept: a synthesis of critique and counter-arguments. Conservation Letters 7 (6):514-523. https://doi.org/10.1111/conl.12091

Segi, S. 2013. The making of environmental subjectivity in managing marine protected areas: a case study from southeast Cebu. Human Organization 72(4):336-346. https://doi.org/10.17730/ humo.72.4.b34794j6u00m0545

Shah, M., and A. R. Cummings. 2018. Comparing logging and subsistence values of plants across an indigenous peoples' influenced landscape. Ecological Indicators 95:165-175. https:// doi.org/10.1016/j.ecolind.2018.06.045

Stålhammar, S., and E. Pedersen. 2017. Recreational cultural ecosystem services: how do people describe the value? Ecosystem Services 26:1-9. http://dx.doi.org/10.1016/j.ecoser.2017.05.010

Steger, C., S. Hirsch, C. Evers, B. Branoff, M. Petrova, M. NielsenPincus, C. Wardropper, and C. J. van Riper. 2018. Ecosystem services as boundary objects for transdisciplinary collaboration. Ecological Economics 143:153-160. https://doi.org/10.1016/j. ecolecon.2017.07.016

Tadesse, G., E. Zavaleta, C. Shennan, and M. FitzSimmons. 2014. Local ecosystem service use and assessment vary with socioecological conditions: a case of native coffee-forests in southwestern Ethiopia. Human Ecology 42:873-883. https://doi. org/10.1007/s10745-014-9704-2 
Trapon, M. L., M. S. Pratchett, and L. Penin. 2011. Comparative effects of different disturbances in coral reef habitats in Moorea, French Polynesia. Journal of Marine Biology 2011:807625. https:// doi.org/10.1155/2011/807625

Turnhout, E., C. Waterton, K. Neves, and M. Buizer. 2013. Rethinking biodiversity: from goods and services to "living with." Conservation Letters 6(3):154-161. https://doi.org/10.1111/ j.1755-263X.2012.00307.X

Walker, B., and M. A. Robinson. 2009. Economic development, marine protected areas, and gendered access to fishing resources in a Polynesian lagoon. Gender, Place, and Culture: A Journal of Feminist Geography 16(4):467-484. https://doi.org/10.1080/0966$\underline{3690903003983}$

Ward, R. G., and E. Kingdon, editors. 1995. Land, custom, and practice in the South Pacific. Cambridge University Press, Cambridge, UK. https://doi.org/10.1017/CBO9780511597176

Yadav, P. K., S. Saha, A. K. Mishra, M. Kapoor, M. Kaneria, M. Kaneria, S. Dasgupta, and U. B. Shrestha. 2019. Yartsagunbu: transforming people's livelihoods in the Western Himalaya. Oryx 53(2):247-255. https://doi.org/10.1017/S0030605318000674

Yonger, M. 2002. Approche de La Pêcherie Récifo-Lagonaire de Moorea (Polynésie Française): Évaluation de La Production Halieutique et de La Population de Pêcheurs. École Nationale Supérieure Agronomique, Rennes, France. 